\title{
Molecular effects on a resilient bacterium surviving in outer space
}

\section{Emanuel Ott}

Yuko Kawaguchi

Denise Kölbl

Elke Rabbow

Petra Rettberg

Maximilian Mora

Christine Moissl-Eichinger

Wolfram Weckwerth

Akihiko Yamagishi

Tetyana Milojevic

\section{Video Byte}

Keywords: Deinococcus radiodurans, Low Earth orbit, proteomics, transcriptomics, metabolomics, molecular stress response, bacteria, outer space, vacuum, stress tolerance, microbes, International Space Station, Tanpopo, Tanpopo mission, desiccation, radiation, freezing, microgravity, extremophiles, DNA damage, reactive oxygen species, environmental stress, extreme environments, extraterrestrial life, Microbiome

Posted Date: November 13th, 2020

DOl: https://doi.org/10.21203/rs.3.rs-107492/v1

License: (c) (i) This work is licensed under a Creative Commons Attribution 4.0 International License.

Read Full License 


\section{Abstract}

Since the dawn of space exploration, we have been fascinated by the survivability of terrestrial life in outer space. Outer space is a hostile environment for any form of life, but some extraordinarily resilient bacteria can survive. Despite galactic cosmic and solar UV radiation, extreme vacuum conditions, temperature fluctuations, desiccation, freezing, and microgravity, the extremophilic bacterium Deinococcus radiodurans withstands the drastic influence of outer space. A recent study examined the molecular effects of space on this unique microbe. After one year of exposure to low Earth orbit outside the International Space Station during the Tanpopo mission, researchers found that D. radiodurans escaped morphological damage, forming numerous outer-membrane vesicles. A multifaceted protein and genomic response was initiated to alleviate cell stress, helping the bacteria to repair DNA damage and defend against reactive oxygen species generation, and processes underlying transport and energy status were altered in response to the environmental stress. These results help us to understand the mechanisms and processes through which life can exist beyond Earth, expanding our knowledge of how to survive and adapt in the hostile environment of outer space. 